\title{
Voices of Teachers Teaching Primary Learners with Hearing Impairment in a Special School in Eswatini
}

\author{
Thembi Motsa Racheal Mafumbate* \\ University of Eswatini, Department of Educational Foundations and Management, Faculty of Education
}

\begin{abstract}
The purpose of this study was to explore the voices of teachers teaching primary learners with hearing impairment in a special school in Eswatini. The sub-objectives were to establish the challenges that were encountered by teachers teaching learners with hearing impairments in Eswatini; and to identify the intervention strategies that can be used to overcome the challenges of teaching learners with hearing impairment in special school. The study was qualitative in its approach, and case study design was used. Purposeful sampling was used to select a sample of fifteen participants comprising 13 teachers and 2 administrative teachers. The researcher used a semi-structured interview guide and focus group discussions as her primary tools for data collection. The administrators were interviewed while the 13 teachers were placed in two focus group discussions. The study revealed that the learners were struggling to understand the content of the current curriculum. The study also revealed that there was lack of collaborative materials appropriate for effective teaching of learners with hearing impairment. The findings of the study revealed that some of the key challenges encountered by teachers were overcrowded classroom; unstable curriculum; and lack of equipment.
\end{abstract}

Keywords: Hearing impairment, collaborative materials, teachers' attitudes.

DOI: $10.7176 / \mathrm{JEP} / 10-34-09$

Publication date: December $31^{\text {st }} 2019$

\section{BACKGROUND}

Learners with hearing impairment may have partial or full hearing loss on one or both ears. The characteristics exhibited by the learners depend on the degree of hearing loss and the onset of that loss. According to Chimedza and Petersen (2014), the earlier the hearing loss manifests itself in a child, the more difficulty he or she will have in developing the spoken language. A hearing handicap or deafness involves not only the loss or impairment of hearing, but the loss or limitation of the ability to acquire language and speech naturally or spontaneously (Bryman, 2016). Impaired or total lack of language has serious implications for the child's development.

A study conducted by Mathers, Smith and Concha (2016) revealed that hearing impairment is the most common sensory deficit in human populations, affecting more than 250 million people in the world. This was affirmed by the World Health Organization, which estimates that in 2005 the number of people in the world with hearing impairments was 278 million, or about $4.3 \%$ of the world's population (WHO, 2005). Irwin (2015), noted that hearing loss is more common in the ageing population as compared to young adults. Individuals are not protected from other causes of hearing loss just because they are at work. Their hearing may therefore be at risk from causes not related to their occupation. However, the U.S. Department of Education (2007) felt that hearing impairment is also a growing trend amongst children. Each year in the United States, more than 12,000 babies are born with a hearing loss; often, the cause is unknown. Hearing loss and deafness can be either: acquired, meaning that the loss occurred after birth, due to illness or injury; congenital, meaning that the hearing loss or deafness was present at birth or may also be a characteristic of another disability such as Down syndrome, Usher syndrome, Treacher Collins syndrome, Crouzon syndrome, and Alport syndrome. In all cases, early detection and treatment are very important to the child's development (U.S. Department of Education, 2007) because language and communication skills develop most rapidly in childhood. When hearing impairment goes undetected, children are delayed in developing these skills.

In Zimbabwe, Mpofu and Chimhenga (2012) established that learners with Hearing Impairment (HI) are experiencing challenges in most learning institutions of Zimbabwe. Most schools that enroll them do not cater for their special needs. Some of their challenges are not detected until too late and as a result, the hearing losses in these pupils become a hindrance in their learning process. This is corroborated by a study conducted by Johnson, Liddell and Erting (2012) who established that upon entering school, the hearing-impaired learners are already well behind non-hearing-impaired age-mates in the acquisition of the knowledge and information expected to be held by children of their age. With each subsequent year in school, they would fall further behind non-hearing-impaired children, especially if they do not have access to the language used in school (Marschark and Spencer, 2010).

Musengi (2013) argues that, hearing impaired learners are not only identified later and receive intervention services only when they begin school, but they also have to leave the only hearing aids they have when they go home on vacation as these costly devices belong to the school.

Teachers in most primary and high schools in Eswatini are not sufficiently trained in sign language for 
education. Others are professionally unqualified, especially in schools found in the remote rural areas. The success in the provision of teaching to learners with disabilities depends on the quality of teaching. Learners with special needs education faced a lot of problems in most of the primary and high schools in Eswatini. Their being at special schools is not well recognized and their needs are not well known. Equal and quality education is the right of every child who attends school. The provision of education should be equal to all learners regardless of their different abilities. According to Mathunjwa (2014), Eswatini is at present offering free primary education for some learners with different disabilities including visual impairment, hearing impairment, mental retardation, physical impairment, autism and multiple disabilities in both special and integrated schools.

The Government of Eswatini, through the Ministry of Education and Training recognises the rights of persons with disability; the learners with hearing impairment included, having access to good and quality education. Through the 2011 policy document, the Ministry of Education and Training stresses the need to ensure that there is equality of educational opportunities for learners with Special Educational Needs. The policy further emphasizes the need to provide education of particularly good quality to pupils with special educational needs (Ministry of Education, 2011).

In Eswatini the issue of Special Needs Education has been tiled. Programmes on how to teach learners with hearing impairment in some colleges do not put much prominence on sign language. In fact sign language, which is supposed to be taught as a language is simply taught as only a component in the programme. This limit the educators the necessary equipment to use in schools where learners with hearing impairment exist. In Eswatini in as much as studies have been conducted on learners with hearing impairment, most of them have not established much on the voices of teachers teaching primary learners with hearing impairment in a special school of Eswatini. However, Vilakati (2012) indicated that learners' language had limited vocabulary. They also have problems in fluency making learning difficult as subjects are learned in sign language.

\section{STATEMENT OF THE PROBLEM}

Since the United Nations Declaration of Education for All (UNESCO, 1995), the practice and implementation of the inclusion has become the main challenge and tension for many countries worldwide. The education system in Eswatini is also undergoing some major reforms. One of these key reforms is aimed at increasing universal access to education, including children with disabilities (EDSEC, 2011). Learners with hearing impairment have been marginalized due to their disability. In the Kingdom of Eswatini, there is only one primary school for learners with hearing impairment which was established in 1975. The learners sit for their primary certificate external examinations, every year, and quite a number of them are usually not successful. According to the Examinations Council of Eswatini Statistics for Centres, (2014) the school for the deaf recorded a 70\% failure rate for the last six consecutive years. In as much as this has been a major concern to the Ministry of education and Training, it has not reached a point where studies could be undertaken in establishing the main reasons for such performance. The researcher has decided to undertake this study to establish the voices of teachers teaching primary learners with hearing impairment in a special school in order to establish the main cause of the learners' poor performance in the Lubombo region.

This study sought to establish challenges encountered by teachers teaching primary learners with hearing impairments of Eswatini.

\section{THEORETICAL FRAMEWORK}

The study was guided by Holcomb's (1968) Total Communication (TCT) theory. Total communication theory incorporates a number of techniques of communication. For instance learners with hearing impairments are exposed to sign language, speech, lip reading, pictures, mime, and writing. The philosophy of Total Communication is that the techniques should be fitted to the learner instead of the other way round. For example, learners with hearing impairment have individual needs such as limited sign language vocabulary. It is observed in the Total Communication Theory that learners with hearing impairment in traditional learning environments often feel left out of classroom communication from the gap that exists between the delivery of the information and the signing of the content by the teacher. Learners with hearing impairment also faced difficulty in responding to the teacher's questions. Therefore, Total Communication assist learners with hearing impairment by giving them a number of options for communication, and then learners are able to express themselves.

The total Communication Theory helps the teacher to engage all possible techniques of communication to enhance the learning experiences. The theory has also been thought to be ideal for this particular study as it contributed to the understanding that techniques of communication need to be adjusted based on the situation. For example, signing may be the right method to use some times; it maybe speech in other situations, and writing may be the best technique in others. Thus, Total Communication is favored by teachers as it is a catch-all that ensures that a learner with hearing impairment has access to some means of communication (speaking as needed or signing as needed). For instance, a learner with hearing impairment who could not communicate well orally will get additional support of sign language and vice versa. 


\section{METHODOLOGY}

The study followed an interpretivism paradigm and used a qualitative approach. The research design for this study was a descriptive case study. A descriptive case study is the type of research design which is focused and detailed in which proposition and questions about a phenomenon are carefully scrutinised and articulated at the outset (Jackson, 2009; Denzin \& Lincoln, 2011). The researcher has adopted the case study design for this study because it was eligible when the researcher intended to collect data on occurrences such as opinions, attitudes, and feelings and habits (Creswell, 2012). One of the advantages of a case study is that it produces qualitative accounts. For that reason, the researcher envisages that the case study research design was most likely to allow for an in-depth analysis of the voices of teachers teaching in a special school primary for learners with hearing impairment in this particular study.

The researcher has targeted to conduct the study on fifteen (15) teachers from the Special School Primary for learners with hearing impairment in the Lubombo region of Eswatini.

Purposive sampling was appropriate for this study because it allows for an effective selection of participants who were rich in information regarding the experiences of teachers who interact with learners with hearing impairments. The use of purposive sampling enabled the capturing and describing of central themes from participants' view points. There were twenty-five (25) teachers in a special primary school for learners with hearing impairment. The researcher decided to sample fifteen teachers who have been in the school for more than two years.

The researcher identified three techniques of data collection which were: the in-depth interviews, document analysis and focus group discussions. Interview questions were open-ended, while information interview questions were open-ended or semi-structured and were conducted face to face. Documents analysis are any written material that has been produced. They are used to supplement information obtained by other methods. The information obtained from documents may be for the past, present and future events. A focus group interview is the process of collecting data through interviews with a group of people, usually four to six (Creswell, 2012). The researcher asks a small number of general questions and prompts responses from all individuals in the group. The participants were able to discuss the questions effectively, modifying each other's ideas such that a collective significance was understood during the session.

\section{RESULTS AND DISCUSSION}

\section{Challenges Encountered by teachers}

It emerged from the study that the curriculum was believed to be unsuitable and over loaded with content that learners cannot master at once. In this regards one part even indicated that "In my opinion the current curriculum is not suitable because it does not consider the special conditions affecting the learner..." Such findings can be viewed as complementary to Maseko and Fakudze (2014) whose study suggests that for teachers to cope, they need to adjust structures and school curricula to make them more favourable for special needs learners' learning process. Based on the findings of the study and the supporting literature, there may be need to review the curriculum currently in use with a view of adjusting it to best achieve the reviewed goals.

Additionally, it was the view of the majority of the teachers that the learners were struggling to understand the content sent within the current curriculum. "In my view most of the content is abstract for the learners and both teacher and learner are not competent in sign language, and this make it very difficult for the content of the curriculum to be explained effectively and covered efficiently to ensure that learning objectives are met" Such findings appear to be very much consistent with the finding of El-Zraigat and Smadi (2012) whose study established that teachers who teach hearing impaired learners suffer from the lack of basic skills necessary to make curriculum adjustment and participating in assessing these learners. Because of their preparation programs at universities where they graduated, they are qualified for teaching regular learners not deaf and hard-of-hearing learners, in other words, those teachers are prepared and trained to be regular teachers not special education teachers. The challenge is that with time teachers without skills become frustrated.

Regarding the lack collaborative materials, the majority of the teachers indicated that the materials to teach were scarce. "It is known the world over that Special needs education in inclusive settings is highly effective if there are adequate collaborative materials for learners and teachers to demonstrate and reach the set learning goals. In this school such materials are scarce to find...." Such findings directly correspond to the findings made by Kenyan study done by Muiti (2010) who posits that the availability of teaching and learning materials for both the learners and the teacher is a challenge. Lack of school resources actually leads to poor teaching methods as teachers and learners are not able to expose themselves to these resources in order to have effective teaching and learning. Adane (2013) suggests that inadequacy of materials and equipment may have adverse effects to learners who are hearing impaired especially the hearing devices for those who are deaf. These materials therefore should be adequate enough to allow learners to effectively use them. The findings of the study therefore support what other studies have established. In practice, teaching learners with special needs requires significant investment in infrastructure and equipment, without this investment it can be had to meet the 
outcomes of the curriculum and ultimately affect education quality.

This study identified several challenges which are influenced by multiple factors that prevented student with hearing impairments from excellent academic performance. Challenges included overcrowded classroom as well as an unstable curriculum and lack of equipment. Similar to Szymanski et al's (2013) findings, regarding lack of supporting equipment such as hearing aids, Aidoo (2011) held a study in Ghana and discovered that the majority of learners with hearing aid were disadvantage by poverty to the extent that such equipment was out of reach for their parents. The findings of the study therefore complement what researchers such as Aidoo (2011) have established concerning availability of supporting equipment.

Furthermore, it was the evidence of the study that some of the teachers lacked the required experience to assist learners with hearing impairment and this was a major challenge in their work. "Some of our teachers lack experience to effectively assist learners with hearing impairment...” in this study findings El-Zraigat and Smadi (2012) who posit that teachers of hearing impaired learners suffer from the lack of basic skills necessary for participating in assessing these learners. Teachers need specialized training to be able to conduct classes effectively, as it is not enough to have learnt a general inclusive education module in pre-service training. Furthermore, Nikolaraizi (2013) found that teachers have a lack of appropriate in-service training needed for working with learners with hearing impairment; furthermore, he indicated that those teachers face problems in their work with learners who are deaf like feeling insecure and unsupported, and making an extra effort in communicating learners with hearing impairment. Another study carried out by El-Zraigat (2010) discovered that learners with hearing impairment require special services which must be offered by qualified and skilled teachers in order to respond to their unique needs. When teachers lack the necessary training and competences to effectively conduct their classes they become stressed and frustrated and this can have a negative influence on the whole learning process of learners with hearing aids.

It was agreed by the majority of participants that it was extremely important for parents to be more involved in the learning processes of the learners with HI. One participant indicated that: "Parents are our actually partners in the successful teaching of such learners, not only do they give confidence the learners, they also ensure that continuity of the learning process is achieved..." This was also supported by the administrators in the study. In line with such findings, Hintermair (2016) posits that family participation is critical in the teaching the hearing-impaired learners. However, teachers express a hopeless feeling about the relationship between them and the families of learners who are deaf and hard-of-hearing. Just as the current study discovered, the parents' involvement is at the minimal level from the teachers' perspective. "Unfortunately some parents "dump" the children here and do not get involved, it's all for the school to do and this is difficult....." ElZraigat and Smadi (2012) adds that even when teacher may send many invitations to the parents, they do not come and do not ask about their children progress. Sometimes, the school year start and end with no visit to school from many learners parents. Therefore, the parents are not participating in making educational decisions related to their children with hearing loss. The findings of the study appear to complement the findings made by researchers such as Hintermair (2016).

\section{INTERVENTION STRATEGIES}

It was proposed that teachers needed training in order to develop their current skills in the teaching of learners with hearing impairment. In this regard one participant said that: "As teachers we continuously need our skills developed. There is need for more workshops to be given for teachers in this school..." Findings are consistent with the findings made by Qaryouti (2010) who establishes that it is within the best interest of national governments to ensure teachers are adequate training and skilled in teaching learners with various disabilities including those with hearing impairment suggests it there makes sense that pre-service training include rigorous skills for working effectively with diverse deaf and hard-of-hearing learners. For teachers already in the system it is key that they receive the necessary in service training to enhance their competence.

Furthermore the head teachers also indicated that: "Indeed frequent in-service training is needed to ensure that teachers are well equipped to fully assist learners. This however up to the INSET department because the only thing we can do is to indicate the need for the training...." Finding in this study concur with Mahwish, Mahr, Ghulan Fatima, and Misbah (2012) who found that the concept of training is critical to meaning the needs of learners with hearing impairment. Teachers need to be able to communicate effectively with the learners even beyond class exchanges. Beyond general communication teachers need to teach learners with hearing effectively and to this must be done using sign language as the predominant means of communication.

The study also revealed that provision of concrete materials was supported by the majority of the participants. In this regard one participant had this to say: "I am a big supporter of concrete materials in teaching learners with special needs because I have had experience where it has worked...." Adoyo (2015) in his study revealed that teachers should use the latest techniques and materials for instruction when working with learners with hearing impairment. More emphasis should be laid on showing the practical things to learners, so that they can easily understand the lesson. More so, teachers should try to develop activities that involve all the 
learners together as this helps to keep a healthy and collaborative interaction of learners with hearing impairment with their peers in the classroom.

The provision of hearing aids was also supported by many of the participants and this can be seen as very consistent with the views of Chimedza and Peterson (2014) who observed that the provision services and resources will make the life of teachers easier during the teaching process. These include well designed educational programmes, learning materials, assistive devices, professional development for all teachers' involved, general and special educators alike among other provisions.

\section{CONCLUSION AND RECOMMENDATIONS}

From the findings, a number of conclusions can be reached. It is conclusive that the curriculum in current use does have not suitable content to meet the learning needs of learners with hearing impairment. It is also conclusive that learners are struggling to understand the content of the current curriculum. Another conclusion of the study is that there is inadequate collaborative materials appropriate to effective teach learners with hearing impairment, this made teaching and learning quite challenging. It was another conclusion of this study that the teachers lacked the required experience assist learners with hearing impairment and this was a major challenge in their work. It was also conclusive that there was limited parental involvement and this was a major challenge affecting the teaching of learners with hearing impairment.

Following the findings, the following recommendations are suggested to meet the needs of all learners:

It is recommended that the INSET department provides teachers in special schools with training specifically focused on developing the skills of teachers in interacting and teaching learners with Hearing Impairment. It is recommended that the government of Eswatini, through the Ministry of Education and training may invest in the provision of adequate facilities and teaching and learning materials to improve the quality of education for learners with Hearing Impairment in schools.

The Ministry of Education may engage a research consultant to explore the suitability or unsuitability of the current curriculum for learners with hearing impairment. Such a study will verify the accuracy of the claim that the current curriculum is not suitable for learners with hearing impairment.

Schools should actively engage the parents of learners with hearing impairment through the introduction of a more intensive parental involvement programme. This will increase the level of parental engagement which benefits the learning and teaching processes of learners with Hearing Impairment.

\section{REFERENCES}

Adane LO (2013). Factors affecting low academic achievement of pupils in Kemp Methodist Junior High School in Aburi, Eastern Region (Unpublished M.Phil thesis). University of Ghana, Legon.

Aidoo D. (2011). An analysis of the manangement of state-maintaines special schools for children with hearing impairment in Ghana. University of Bath. PMCid : PMC4821879.

Adoyo, P. (2015). Educating deaf children in an inclusive setting in Kenya: Challenges and Considerations. International Journal of Deaf Studies, 123, 174-224.

Bell, J., Waters, S., \& Ebooks Corporation. (2009). Doing your research project: A guid for first-time researchers (sixth ed.). Maidenhead, Berkshire: Open University Press.

Bryman, A (2016) The Research Social Research Methods 5th Edition Social Research Oxford University Press.

Chimedza, R. and Peterson, S. (2013). Disabilities and Special Needs Education in an African Setting. Harare: College Press.

Coombs, B. (2014). Successful Teaching. A practical Handbook. Ibadan: Heinemann Educational Books. (KCAASE) blooms taxonomy of cognitive domain.

Cresswell, J. W. (2012). Educationa Research: Planning Conducting, and Evaluating Quantitative and Qualitative Research. Upper Saddle Rver, NJ: Prentice Hall.

Denzin,N. K., \& Lincoln, Y. S.(Eds.). (2000a). Handbook of Qualitative research (2 ${ }^{\text {nd }}$ ed.). Thousand Oaks, CA: SAGE.

Eisner, N. (2012). Engaging Deaf and Hard of Hearing Students in the School Library: A Handbook for Teacher-Librarians. University of Illinois at Urbana-Champaign, Graduate School of Library Information Science.

El-Zraigat, I., and Smadi, W. (2012). Challenges of Educating Students Who are Deaf and Hard-of-Hearing in Jordan. International Journal of Humanities and Social Science, Vol. 2 No. 8.

Eriks-Brophy, A. \& Whittingham, J. (2013). Teachers' perceptions of the inclusion of children with hearing loss in general education settings. American Annals of the Deaf,158. http://muse.jhu.edu.lynx.lib.usm.edu/journals/american_annals_of the_deaf/v158/158.1.eriks-brophy.html

Fakudze, S., Maseko,N. (2014). Supporting teachers to implement inclusive education in Kwaluseni District, Swaziland.

Franklin, M. I. (2012). Understanding Research: Coping with the Qualitative-Quantitative divide. London: 
Routledge.

Hintermair, M. (2016). Parental resources, parental stress, and socio-emotional development of deaf and hard-ofhearing children. Journal of Deaf Studies and Deaf Education, 11 (4), 493-513.

Holcomb, R. (1968). Total Communication use among Elementary teachers of hearing impaired children. American Annals of the Deaf, 135, 257-263.

Irwin, J. (2015). What are the causes, prevention and treatment of hearing loss in the ageing worker? Occupy. Journal Med. Vol. 50, No. 7, pp. 492-495, 2000.

Johnson, R., Liddell, S., \& Erting, C. (2012). Unlocking the Curriculum: Principles for Achieving Access in Deaf Education. Washington, DC: Gallaudet University.

Koustoubou, M. (2014). Deaf ways of writing narratives: a bilingual approach. Netherlands: Springler.

Leedy, P.D. and Ormrod, JE. (2010). Practical Research: Planning and Design. 7th ed. USA: Prentice Hall.

Mackber, H. (2010). Research into teacher's effectiveness. London: Department for Education and employment.

Mahwish S., Mahr M. S. A., Ghulan Fatima, misban M. (2012). Problems faced by students with hearing impairment in inclusive education" Journal of research and reflection in eduction 129-136."

Maseko, N., Fakudze, S. (2014). Surpporting Teachers to inclusive Education. Mediterenean: Journal of Social Sciences MCSER, Publishing, Romen-Italy 613-521.

Marschark, M., and Spencer, P. (2010). Promises (?) of deaf education: From research to practice and back again. In M. Marschark \& P. Spencer (Eds.), The Oxford Handbook of Deaf Studies, Language and Education (Vol. 2). Oxford: Oxford University Press.

Mastropieri, M.A. \& Scruggs, T.E. (2010). The Inclusive Classroom: Strategies for Effective differentiated Instruction. New Jersey: Upper Saddle River.

Mathers, C. Smith, A and Concha, M. (2016).Global Burden of hearing Loss. London: Research Gate.

Mitchell, D. (2015). Contextualising inclusive education, evaluating old and new international paradigms. London: Routledge Falmer.

Ministry of Education and Training (2008). Inclusve Education Draft Policy. Mbabane. Swaziland Government.

Ministry of Education and Training. (2011).Ministry of Education and Training sector Policy (EDSEC): Mbabane, Swaziland Government.

Ministry of Educatioan and Training. (2014).The Special Education Needs (SEN) Unit.Mbabane. Government of Eswatini.

Mpofu, J., and Chimhenga, S. (2012). Challenges faced by Hearing Impaired pupils in learning: A case study of King George VI Memorial School. IOSR Journal of Research \& Method in Education: Volume 2, Issue 1 2320-7388.

Mtuli,T (2015) The challenges of teaching and learning of hearing impaired learners enrolled in regular primary and secondary schools in Tanzania. Open University: Tanzania.

Muiti, J.M. (2010). Hindrances to effective learning of pupils with hearing impairments in Meru North District, Kenya. (Unpublished Master thesis) Kenyatta University: Nairobi, Kenya.

Musengi, M., Ndofirepi, A., \& Shumba, A. (2013). Rethinking Education of Deaf Children in Zimbabwe: Challenges and Opportunities for Teacher Education. Journal of Deaf Studies and Deaf Education, 18 (1), 62-74.

Musengi, E.,\&Musengi,M.(2014).Oral history of a pioneer school for the deaf in Zimbabwe:A research based report. Johannesburg:University of Witwatersrand.

Ndikumwami,M. (2004).Investigation of challenges that face teachers in improving teaching performance in primary schools: a case of Dodoma municipal council. Open University: Tanzania.

Nikolaraizi, M. (2013). The need for specialist training in the education of deaf children in Greece: Listening to teachers' perceptions. Mediterranean Journal of Educational Studies, 5 (2), 19-38.

Qaryouti, I. A. (2010). Inclusion of the disabled students in education. International Journal of CrossDisciplinary in Special edution (IJCDSE) VOL 1 (4) 216-222 [2].

Robbins, S.P. (2011). Organization Behaviour. New Jersey: Prentice Hall Inc.

Russell, D. (2010). Inclusion or the illusion of inclusion: A study of interpreters working with deaf students in inclusive education settings; University of Alberta, Canada.

Shirfin, M.S. and Polania, K.A. (2007). "Adolescents who are deaf or hard of Hearing: A Communication Perspective on Educational Placement". Journal Topics in Language Disorder, Volume 20 (2): 58-73.

Swaziland, E. C. (2014). Statistics for Centres. Zulwini: ECOS.

Szymanski C, Lutz, Shahan C, Gala N. (2013). Critical needs of students who are deaf and hard of hearing: A public input summary. Washington, DC: Gallaudet University, Laurent Clerc National Deaf Education Center.

Training, M. o. (2011). Swaziland Education and Training Sector Policy. Mbabane: Ministry of Education and Training.

UNESCO. (1995). Salamanca statement. Paris: UNESCO. 
UNESCO (2015). Teaching Children with Disabilities in Inclusive Settings. Embracing Diversity: Toolkit for Creating Inclusive, Learning-Friendly Environments Specialized Booklet 3. UNESCO Bangkok Office, France.

U.S. Department of Education. (2007). 27th annual report to Congress on the implementation of the Individuals with Disabilities Education Act, (Vol. 2). Washington, DC.

Vilakati, L, B. (2012) Insight into the Teaching Strategies for Hearing Impaired Learners: A Case Study of Primary and Junior Secondary Science. Unpublished Thesis. University of Swaziland.

Wallen, N. E, \& Fraenkel, J. R. (2011). Educational Research: Aguid to the process. New Jersey: Elbaum Associates, Inc.

World Health Organization (2005). Deafness and hearing impairment.

http://www.who.int/mediacentre/factsheets/fs300/en/index.html.

Yin, R. k. (2014). Case study research; Design \& Methods. Thousand Oaks: SAGE Publications. 